AUTORES:

António Manuel Fonseca ${ }^{1}$

Cláudia Dias ${ }^{1}$

Nuno Corte-Real ${ }^{1}$

${ }^{1} \mathrm{CIFI}^{2} \mathrm{D}$, Faculdade de Desporto Universidade do Porto, Portugal

https://doi.org/10.5628/rpcd.10.02.96

\section{Da participação ao abandono da prática desportiva.}

\section{PALAVRAS CHAVE:}

Crianças e jovens. Participação no desporto.

Benefícios. Abandono. Enquadramentos

conceptuais.

\title{
RESUMO
}

Reconhecendo o impacte positivo exercido pela prática desportiva regular no desenvolvimento harmonioso e equilibrado das crianças e dos jovens, este artigo procura, a partir de uma revisão narrativa da literatura existente neste domínio, não só enfatizar os benefícios daquela prática, mas também alertar para a necessidade de se melhorar a compreensão sobre o fenómeno do abandono desportivo, o qual parece atingir uma dimensão demasiado elevada. Nesse sentido, são discutidas questões relativas à necessidade da correcta identificação da sua magnitude bem como das variáveis que the estão subjacentes, convocando-se para o efeito alguns dos enquadramentos conceptuais considerados como mais úteis neste contexto. 
From participation

to dropout of sport.

\section{ABSTRACT}

Recognizing the positive impact of a regular sport practice in the harmonious and balanced development of children and youth, this paper seeks, through a narrative review of the literature of this area, not only emphasize the benefits of that practice, but also warns to the need to improve the understanding of the phenomenon of the dropout of sports, which seems to have a size too large. Accordingly, are discussed issues relating to the need for proper identification of its magnitude as well as the variables that underlie it, convening to this effect some of the conceptual frameworks considered most useful in this context.

\section{KEY WORDS:}

Children and youth. Sport participation. Benefits. Dropout. Conceptual backgrounds. 


\section{DOS BENEFÍ́CIOS \\ DA PRÁTICA DESPORTIVA}

Actualmente, constitui-se como um dado inegável e incontornável o reconhecimento dos múltiplos benefícios inerentes a uma actividade desportiva regular e sistemática dos indivíduos em geral, e das crianças e dos jovens em particular $(20,27,70,88)$. Na verdade, tanto a comunidade científica especializada no âmbito do desporto infanto-juvenil como a população em geral coincidem na convicção de que o contexto desportivo é um cenário apropriado para o desenvolvimento físico, mas também para o fomento de hábitos saudáveis, valores morais ou recursos psicossociais ${ }^{(7)}$.

No plano físico e biológico, os defensores da actividade desportiva destacam que esta é geralmente acompanhada de diversos benefícios, relacionados com a aquisição de hábitos motores, aumento da capacidade física, força e resistência e desenvolvimento muscular e ósseo ${ }^{(73)}$. Estudos realizados por diversos investigadores demonstraram que a actividade física (ainda que em diversas formas e com diferentes níveis de intensidade) se associa, por exemplo, a um decréscimo nos riscos de cancro no cólon ${ }^{(44)}$, de ataques súbitos ${ }^{(56)}$, da hipertensão ${ }^{(77)}$, ou de doenças cardíacas ${ }^{(59)}$. Para Blair e colaboradores ${ }^{(4)}$, a aptidão física está mesmo associada a mais baixos índices de todas as causas de mortalidade.

Estes dados são tanto ou mais relevantes se nos consciencializarmos, por exemplo, que têm vindo a ser encontradas evidências no sentido de que, de uma forma geral, as doenças coronárias e hipertensão têm origem na infância e adolescência. Por outro lado, numa altura em que o aumento da prevalência da obesidade em crianças e adolescentes, geralmente associado a um estilo de vida sedentário, se torna cada vez mais comum nas sociedades modernas, a prática regular e sistemática de uma actividade desportiva pode também ser determinante no controlo do peso dos indivíduos. A este propósito, importa salientar que diferentes investigações têm salientado que todas as causas de mortalidade e doenças coronárias na infância e adolescência assumem um significado mais elevado quando associadas a excesso de peso na infância ${ }^{(51)}$.

No entanto, as vantagens do envolvimento na prática desportiva não se esgotam nas melhorias físicas ou biológicas que daí podem advir. Com efeito, a actividade desportiva promove também benefícios a nível psicológico e emocional, sendo diversos os estudos que identificam a existência de uma relação entre aquele tipo de actividade física e a saúde mental das pessoas nele envolvidas, designadamente no que concerne a uma redução de sintomas de depressão, stress e ansiedade ${ }^{(16,20,50,52)}$.

No caso das crianças e dos jovens, as vantagens psicológicas da participação no desporto podem ser ainda mais profundas e penetrantes. Efectivamente, é durante este período da vida que são desenvolvidas importantes atitudes, por exemplo, acerca da realização, da autoridade, da conformidade, da subordinação, da responsabilidade, do compromisso pessoal e da persistência em face da adversidade para atingir objectivos a longo prazo. 
Além disso, o desporto ajuda a desenvolver competências de autocontrolo e autoaceitação, ensinando as crianças e jovens a lidarem igualmente com o sucesso e com o fracasso, promovendo o desportivismo e o respeito pelos outros, e sugerindo formas alternativas de competir e cooperar com outras pessoas. Do mesmo modo, refira-se o seu enorme potencial no que respeita ao fomento da autoconfiança, autoconceito e autoestima, assim como

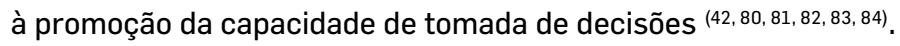

Importa igualmente não esquecer que, na medida em que muitos dos requisitos sociais e morais para a participação no desporto são similares aos requeridos para um correcto e desejável funcionamento das pessoas em sociedade, o desporto constitui, ou pode constituir, uma excelente oportunidade educativa para o desenvolvimento social das crianças e adolescentes ${ }^{(73)}$.

A este propósito, Smith e colaboradores ${ }^{\left({ }^{83}\right)}$ afirmam que a actividade desportiva se pode definir como uma situação de vida em miniatura, em que os jovens atletas aprendem, através da vitória e do fracasso, a lidarem com realidades que irão enfrentar na sua vida futura. Praticando desporto, as crianças e adolescentes desenvolvem igualmente maiores capacidades para enfrentar o stress, tolerar a frustração e adiar a obtenção de recompensas; simultaneamente, podem aprender e desenvolver competências de interacção social, sendo um contexto onde a unidade familiar pode ser reforçada ${ }^{(5,79,84)}$.

Ainda assim, será avisado reconhecer que a participação no desporto, por si só, não resulta necessariamente no desenvolvimento de características sociais positivas; estas consequências só se tornarão realidade se derivadas de experiências desportivas que promovam experiências positivas e minimizem experiências negativas ${ }^{(73)}$.

Da análise da literatura e investigação mais especializada avultam igualmente evidências de que a participação no desporto tem implicações positivas no desenvolvimento educacional, parecendo, ao contrário de alguma crença mais generalizada, encorajar as crianças a permanecerem mais tempo na escola e ajudá-las a tornarem-se melhores estudantes, quer no ensino básico, quer no secundário - uma contribuição que não se pode minimizar, num mundo em que ocorrem frequentes mudanças sociais e económicas que colocam uma grande ênfase nas competências de aprendizagem e adaptação ${ }^{(65)}$. Isto não significa que a prática desportiva torne os estudantes mais "espertos" ou "inteligentes", mas sim que contribui para que eles se tornem mais produtivos, porquanto se tornam mais fortemente motivados, mais organizados e eficazes em tarefas de desempenho e realização, competências essas que podem ser transferidas rapidamente para outros papéis sociais, como o de estudante. A médio ou longo prazo, e de um ponto de vista económico, estudantes produtivos tornar-se-ão com maior probabilidade adultos produtivos ${ }^{(20)}$.

Por último, não obstante reconhecermos não ser consensual a assunção de que a participação no desporto contribui para o desenvolvimento moral, consideramos importante destacar a afirmação de Seefeldt e Ewing ${ }^{(73)}$ de que o contexto do desporto se caracteriza pela existência de um elevado potencial para esse desenvolvimento, essencialmente através das 
interacções sociais associadas a um envolvimento e participação regular no desporto. Esta afirmação é apoiada por estudos ao nível da delinquência, que encontraram associações negativas entre a prática desportiva e comportamentos delinquentes e "desviantes", menos incidência de tabaco, drogas, gravidezes não desejadas e abandono escolar ${ }^{(8,71,7576)}$.

Adicionalmente, os programas que incluem actividades desportivas podem também concorrer para o desenvolvimento moral, porquanto constituem importantes oportunidades para o desenvolvimento da liderança, para o desenvolvimento do sentido de comunidade e pertença ${ }^{(41)}$, dos valores de cidadania e, considerando o desejável respeito pela ética de fair play e de adesão imparcial às regras, promovem o respeito pelos outros, especialmente para com os que provêm de diferentes enquadramentos socioculturais ou possuem diferentes capacidades ${ }^{(20)}$.

\section{DA PARTICIPAÇÃO NO DESPORTO}

São, pois, múltiplas e diversificadas as vantagens associadas a um pronunciado envolvimento no desporto e a um estilo de vida fisicamente activo, razão pela qual podem considerar-se como naturais e pouco surpreendentes os resultados de diversas investigações nacionais e internacionais a comprovar uma adesão maciça, empenhada e persistente das crianças e jovens à prática desportiva $(10,24,40,48,49,89)$.

Roberts afirmou, em 1992, que a participação das crianças e dos jovens em alguma forma de desporto organizado atingia o impressionante número de 200 milhões, uma afirmação que parece ser corroborada por dados apresentados em diferentes países.

Assim, por exemplo, nos EUA foi referido, durante a última década do século passado, que aproximadamente metade das crianças e jovens até aos 18 anos participavam em programas desportivos organizados nas suas comunidades ${ }^{(73)}$ e muitos outros milhões em programas desportivos extracurriculares ${ }^{\left({ }^{80}\right)}$. Na mesma altura, Weiss e Hayashi ${ }^{(94)}$ referiram que 40 milhões de crianças e jovens norte-americanas entre os 6 e os 18 anos estavam envolvidos em programas desportivos, escolares e comunitários chegando Brustad (6) a afirmar que 8 em cada 10 das crianças e jovens daquele país participavam, em algum momento das suas vidas, em actividades desportivas.

$\mathrm{Na}$ Europa, os números disponíveis são igualmente expressivos. Enquanto em Espanha $53 \%$ dos jovens praticavam desporto federado e $95 \%$ desporto escolar ${ }^{(60)}$, na Bélgica os dados existentes apontavam para um envolvimento no desporto de $60 \%$ dos jovens até aos 18 anos ${ }^{(19)}$, percentagem ainda assim inferior aos 70/ 80\% reportados no caso da Inglaterra ${ }^{(95)}$. Na mesma linha dos dados anteriores, em França, dos 14 milhões inscritos em federações desportivas em 1997, praticamente $90 \%$ tinham idades compreendidas entre os 14 e os 17 anos ${ }^{(34)}$. 
Dados relativos a um elevado envolvimento das crianças e dos jovens no desporto foram igualmente divulgados nos países nórdicos: assim, foram indicados valores na ordem dos 70 a $80 \%$ na Dinamarca ${ }^{(39)}$ e dos $82 \%$ na Finlândia ${ }^{(47)}$, enquanto na Suécia, foi referido que aproximadamente $66 \%$ dos rapazes e $50 \%$ das raparigas entre os 7 e os 20 anos participavam em actividades desportivas ${ }^{(22)}$.

No que concerne especificamente a Portugal, alguns dos escassos dados existentes apontavam no sentido de que a participação desportiva dos jovens com idades entre os 15 e os 19 anos se situava na ordem dos $50 \%$, sendo que $34 \%$ dos sujeitos se encontravam envolvidos no desporto organizado federado (48).

No entanto, será o panorama da participação das crianças e dos jovens em actividades desportivas tão "dourado" quanto parece decorrer de todas as estatísticas anteriormente referidas? Para além disso, será aquela participação suficientemente regular e sistemática para que eles possam usufruir de todos os benefícios, anteriormente mencionados, associados a essa participação?

Com efeito, o facto de estes dados, de uma forma geral, serem provenientes de estudos transversais e não longitudinais, apenas nos permite constatar que eram muitos os que, na altura a que se reportaram os referidos estudos, praticavam desporto, mas não nos permite saber se aquela prática se prolongou - e prolonga - no tempo, de forma intensa e regular; e essa é, efectivamente, a questão fundamental.

$\mathrm{Na}$ verdade, parece quase desnecessário recordar que os benefícios decorrentes da prática desportiva apenas ocorrerão se, para além de o contexto em que se desenvolve a referida prática reunir em si as condições necessárias para a sua consecução, as crianças e os jovens a realizarem durante um período mínimo de tempo. Não é com uma prática desportiva de uma semana, um mês, ou mesmo um ano, que as crianças e os jovens vão beneficiar, na medida do possível e do desejável, de todas as vantagens potencialmente decorrentes de uma prática desportiva regular, sistemática e continuada.

\section{DO ABANDONO DO DESPORTO}

Logo, parece-nos ser fundamental conhecer o verdadeiro número de crianças e jovens que decidem abandonar uma modalidade desportiva cuja prática tinham iniciado normalmente com elevado entusiasmo, por vezes pouco tempo antes, bem como, naturalmente, as razões que estiveram subjacentes a essa decisão. Na verdade, ainda que sejam relativamente escassas as investigações sobre os factores e processos sociais e psicológicos relacionados com este fenómeno ${ }^{(36)}$, são várias as evidências empíricas e científicas no sentido da existência de um número significativo de crianças e jovens que decidem abandonar a prática desportiva, em aparente contradição com o interesse inicial manifestado 
pelo desporto. Assim sendo, em nossa opinião, a resposta a esta questão deve constituir-se como uma prioridade na agenda de preocupações de todos os interessados e envolvidos no desporto infanto-juvenil.

No que concerne a estatísticas disponíveis sobre este fenómeno, podemos destacar, por exemplo, as estimativas de Roberts e Kleber ${ }^{(62)}$ no sentido de que $80 \%$ das crianças americanas entre os 12 e os 17 anos abandonavam os programas desportivos organizados em que estiveram envolvidas. Outras investigações no mesmo país forneceram suporte para aquelas estimativas, apontando para que a percentagem de jovens que abandonava 0 desporto até aos 17 anos se aproximava dos 80\%, com uma terça parte a fazê-lo após os 12 anos ${ }^{(32)}$. No mesmo sentido, o National Center for Education Statistics ${ }^{(53)}$ identificou na faixa etária dos 14 aos 17 anos a existência de um declínio no número de jovens envolvidos no desporto, em contraste com o verificado com as crianças e os jovens com idades compreendidas entre os 5 e os 13 anos de idade.

Também na Austrália, um estudo sobre o abandono do desporto por parte de jovens australianos na sua transição do ensino secundário para a universidade ${ }^{\left({ }^{(5)}\right)}$ revelou que $72 \%$ dos inquiridos tinham cessado a sua participação desportiva em algum momento das suas vidas, ainda que somente $26 \%$ tivesse abandonado o desporto de forma completa e definitiva; os restantes $46 \%$ tinham terminado a sua implicação num determinado desporto, mas estavam envolvidos noutro diferente.

No continente europeu, os dados são relativamente semelhantes. Assim, na Irlanda, num amplo estudo com mais de 20 mil crianças e jovens, dos quase 7 mil que disseram já terem praticado pelo menos um desporto $20 \%$ tinham abandonado completamente a prática desportiva ${ }^{(46)}$, sendo estes números similares aos encontrados na Bélgica ${ }^{(19)}$. Mais a norte da Europa, concretamente na Dinamarca, investigações realizadas nas modalidades da ginástica e natação apontaram, uma vez mais, para uma elevada taxa de abandono entre as crianças e jovens: enquanto a natação era uma modalidade praticada por uma em cada cinco crianças entre os 7 e os 9 anos, mas somente por um em cada 20 jovens de 13/ 15 anos, na modalidade de ginástica, dois terços dos praticantes entre os 7 e os 9 anos, já não o eram aos 13/ 15 anos de idade ${ }^{(39)}$.

Os resultados de alguns estudos longitudinais realizados em França são também fonte de alguma apreensão no que respeita ao fenómeno do abandono. Uma investigação de natureza longitudinal desenvolvida por Guillet e Sarrazin ${ }^{(35)}$ no âmbito do andebol feminino revelou que $50 \%$ das atletas que tinham começado a praticar a modalidade entre os $9 \mathrm{e}$ os 12 anos abandonavam essa prática 3 a 4 anos depois. De forma semelhante, uma outra investigação longitudinal, durante 10 anos, em atletas com idades compreendidas entre os 13 e os 15 anos, revelou taxas de abandono de $50 \% 2$ a 3 anos após o início da prática, percentagem que se elevava aos $75 \%$ após 5 anos e meio ${ }^{(34)}$. Ainda neste país, mas na modalidade do boxe, um estudo longitudinal de 5 anos realizado por Trabal e Agustini (87) 
identificou uma taxa média de abandono na ordem dos 54\%. Finalmente, uma outra investigação longitudinal, também ao longo de 5 anos, com praticantes de equitação, concluiu que $66 \%$ dos atletas abandonavam antes dos 8 anos de prática, cifrando-se a taxa anual média de abandono nos $40 \%{ }^{(12,13)}$.

Embora uma primeira leitura destes dados concorra naturalmente para a noção de que o fenómeno do abandono do desporto por parte das crianças e jovens assume contornos claramente elevados, importará, em nosso entender - não negando que são obviamente muitos os que decidem abandonar a prática desportiva, com os naturais prejuízos daí decorrentes -, levantar alguma reserva relativamente à efectiva e exacta dimensão das taxas de abandono que normalmente são avançadas a esse respeito.

Com efeito, uma questão central que se coloca neste domínio consiste no facto de a maior parte das investigações publicadas não precisar o que os seus autores entendem por abandono ${ }^{(34,69)}$. Consequentemente, a partir da análise dos referidos estudos não é possível saber se os jovens que indicaram ter cessado a prática desportiva o fizeram em relação ao desporto em termos gerais ou relativamente a uma determinada modalidade e essa é uma distinção importante, atendendo a que "enquanto o abandono total da prática desportiva por parte dos jovens é claramente um desfecho que devemos procurar evitar, atendendo fundamentalmente às claras consequências negativas que daí advêm para eles, o mesmo não se passa necessariamente com o abandono de uma determinada modalidade desportiva quando a esse abandono se sucede a prática de uma outra modalidade desportiva, ou até da mesma modalidade desportiva mas num clube ou num contexto distinto do anterior" (p. 269) (27).

Como anteriormente sublinhámos, quase todos os estudos realizados até ao momento foram de natureza transversal, e não longitudinal, centrando-se essencialmente na análise da variação do número de inscrições num clube ou modalidade de um ano para o outro, razão pela qual são úteis para determinar a taxa de reinscrição das crianças e dos jovens num dado clube ou modalidade, mas não a taxa real de abandono do desporto ${ }^{(27)}$.

A uniformização dos critérios estabelecidos pelos investigadores para definirem o conceito de abandono da prática desportiva, que funcionarão posteriormente como estrutura de enquadramento para a definição de objectivos mais específicos e potencialmente mais comparáveis para os estudos a desenvolver neste âmbito, constitui assim um passo essencial para o aprofundamento do conhecimento relativo a este fenómeno.

Nesse sentido, procurando contribuir para a resolução desta questão, Gould ${ }^{(32)}$ propôs que o abandono desportivo seja considerado em função de um continuum, que inclua 0 abandono de uma actividade desportiva, a mudança para outra actividade e o abandono total da participação desportiva.

Outra questão importante relaciona-se com o controlo da decisão de abandonar a prática desportiva. De facto, embora em certos casos o abandono esteja associado a causas incontroláveis, como as lesões, ou mesmo o conflito com os estudos ${ }^{(32,57)}$, considerando- 
-se a ocorrência de um abandono relutante ${ }^{(43)}$, noutros casos o abandono do desporto decorre da acção de razões controláveis, sendo este tipo de abandono mais frequente e mais merecedor de atenção porquanto a compreensão do que the está subjacente poderá fornecer informação bastante útil no sentido da sua prevenção, bem como, em concomitância, na promoção de uma maior perseverança por parte dos jovens relativamente à sua prática desportiva.

Petlichkoff ${ }^{(57)}$ identificou dois tipos de abandono controláveis pelo desportista: o abandono protagonizado por aqueles que ainda estão satisfeitos com a sua experiência desportiva mas cujo interesse por outras actividades os "obriga" a deixarem a sua actividade - designado de abandono voluntário - e o abandono dos desportistas que decidem parar a prática devido, por exemplo, a uma elevada pressão percebida, agressividade do treinador ou falta de êxito, podendo estes experimentar uma afectividade negativa que os torne mais susceptíveis de suspenderem não só a prática da modalidade desportiva praticada mas, inclusivamente, todo o tipo de prática desportiva.

Ainda em relação a este assunto, Guillet e Sarrazin ${ }^{(34,66,69)}$ definiram cinco tipos de abandono: i) abandono forçado (correspondente ao abandono não controlado pelos indivíduos; por exemplo, devido a lesão); ii) abandono por curiosidade (correspondente ao abandono de indivíduos que só se envolveram na prática desportiva para experimentarem e por pouco tempo); iii) abandono contra o coração (correspondente ao abandono de indivíduos que, embora satisfeitos com a sua actividade desportiva, a suspendem por falta de tempo; por exemplo, devido a obrigações familiares ou laborais ou porque se envolvem noutras actividades mais apelativas; iv) abandono por descontentamento (correspondente ao abandono de indivíduos cuja actividade desportiva não vai ao encontro das suas necessidades); e v) abandono por esgotamento/ burnout (correspondente ao abandono de indivíduos cuja prática desportiva - devido às exigências e contexto em que se desenvolve - lhes origina um significativo cansaço físico ou emocional; por exemplo, devido a uma elevada ênfase na vitória ou pressão dos treinadores, pais ou dirigentes). De destacar ainda que, de acordo com Sarrazin e Guillet ${ }^{(69)}$, estas duas últimas categorias deveriam constituir-se como o objectivo principal da investigação destinada a incentivar a fidelidade dos jovens praticantes.

No que concerne às razões que subjazem à decisão das crianças e jovens abandonarem a prática desportiva, as relativamente escassas investigações realizadas até ao momento, adoptando uma abordagem eminentemente descritiva, destacaram que, de uma forma geral, as crianças e jovens referem que as que maior impacte exercem na sua decisão de abandonar o desporto são "a falta de prazer", a "(in)competência percebida", a "ênfase excessiva na competição", as "lesões" (14,15, 30, 33, 43, 58, 74), o "conflito de interesses" ou "interesse por outras actividades", o "aborrecimento", os "conflitos com o treinador", o "fracasso na melhoria das competências", ou ainda o "não jogar tempo suficiente" $(69,93)$. Adicionalmente, da análise dos resultados dos estudos realizados emerge ainda a cons- 
tatação de que a decisão das crianças e jovens abandonarem o desporto não surge como consequência da acção de uma razão isolada mas sim da acção de um conjunto mais ou menos diversificado de razões.

\section{DOS ENQUADRAMENTOS CONCEPTUAIS}

Todavia, não obstante o interesse e mesmo a importância do conhecimento das razões aduzidas pelas crianças e jovens para cessarem a sua actividade desportiva conseguido através da realização dos estudos anteriormente referidos, os quais de resto convém continuar a desenvolver, importa sublinhar aqui igualmente algumas das críticas que thes têm sido endereçadas. Por exemplo, a circunstância de nalguns estudos os investigadores terem recorrido a instrumentos elaborados por eles próprios integrando um elenco previamente determinado de potenciais razões para o abandono da prática desportiva relativamente às quais foi solicitado às crianças e jovens para indicarem o impacte assumido na sua decisão de abandonar o desporto, constitui-se como alvo de crítica a partir do momento em que o elenco de razões submetidas ao escrutínio das crianças e jovens nem sempre se caracteriza pela necessária abrangência da realidade em estudo.

Do mesmo modo, a circunstância de o agrupamento das diferentes razões ser comandado fundamentalmente por critérios de natureza estatística e não conceptual, decorrentes do recurso a técnicas estatísticas como a análise factorial exploratória, e de serem fundados nestes resultados os modelos teóricos desenvolvidos posteriormente para uma análise mais profunda do fenómeno do abandono do desporto infanto-juvenil é igualmente uma estratégia criticável. A acrescer, o problema de falta de estandardização e especificidade dos instrumentos utilizados nos diversos estudos realizados complica enormemente o estabelecimento de comparações entre estudos ${ }^{(11)}$.

Assim sendo, o facto de a maior parte das investigações ter uma natureza descritiva, ateórica e retrospectiva não tem permitido que o conhecimento neste domínio progrida de modo mais significativo, pois os seus resultados reportam-se a razões do abandono intuitivas, subjectivas e superficiais ${ }^{(36,69)}$. Ou seja, investigar as razões referidas por crianças e jovens como estando na origem da sua decisão de abandonar a prática de uma modalidade desportiva tem interesse, mas não permite compreender plenamente que variáveis e processos diferentes conduzem às razões apontadas, bem como pode inclusivamente induzir-nos em erro relativamente às reais razões que levaram os indivíduos a abandonar a prática desportiva. Por exemplo, a razão "sentia demasiada pressão" pode corresponder quer à atitude do treinador e dirigentes do clube exortando continuadamente os jogadores à vitória, quer à pressão dos pais que obrigam o seu filho a praticar desporto contra a sua vontade. Por outras palavras, diferentes variáveis e processos podem conduzir às mesmas razões superficiais de abandono ${ }^{(69)}$. 
Deste modo, para ultrapassar as limitações inerentes ao conhecimento decorrente da análise das habitualmente designadas de "razões de superfície", importa complementar este tipo de informação sobre o abandono desportivo com outra informação, como seja a que se relaciona com os factores e processos que promovem ou impedem a prática desportiva, o que implica a necessidade de desenvolver investigação baseada em enquadramentos conceptuais robustos e reconhecidamente úteis ${ }^{(27) .}$

$\mathrm{Na}$ verdade, para melhor compreender os factores e processos psicológicos envolvidos no fenómeno do abandono da prática desportiva e promover e aumentar os níveis de actividade física das crianças e jovens, é crucial conhecer o mais profundamente possível os mecanismos relacionados com a motivação para a prática desportiva, já que estas são duas realidades que, embora distintas, estão intimamente relacionadas ${ }^{(11)}$. Assim sendo, a motivação pode ser considerada uma variável chave quando se tenta predizer a participação e o abandono no desporto ${ }^{(91)}$.

Até à data, os investigadores que se têm debruçado sobre a temática da motivação nos mais variados contextos têm elegido como suas prioridades diversas questões mais ou menos relacionadas (e.g., motivos para a participação; motivação intrínseca; expectativas de autoeficácia e de resultado; objectivos de realização; climas motivacionais; concepções sobre a competência; autorregulação do comportamento), recorrendo para o seu estudo a distintos enquadramentos conceptuais.

No caso da investigação desenvolvida em contextos desportivos, os investigadores começaram por se preocupar com a determinação dos motivos que levam os indivíduos à prática de uma determinada modalidade desportiva ${ }^{(1,2,3,17,25,31)}$, conhecimento esse que pode contribuir igualmente para um melhor conhecimento do fenómeno do abandono, porquanto os motivos para a participação e para o abandono se constituem como a cara e a coroa da mesma moeda, isto é, da implicação ou compromisso com o desporto ou da sua desvinculação ou descomprometimento ${ }^{(11)}$.

De uma forma geral, a literatura que resultou dos estudos sobre os motivos que levam os jovens a praticarem desporto, destaca a existência de um leque alargado de motivos importantes para as crianças e jovens praticarem desporto, de entre os quais poderemos realçar os relacionados com o desenvolvimento e a demonstração de competência, a saúde

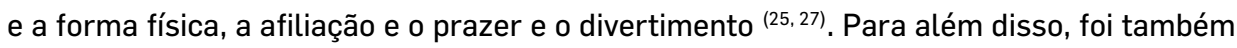
evidente que, geralmente, os jovens apresentam como razão para a sua prática desportiva uma diversidade de motivos e não apenas um único ${ }^{(25,26,28)}$, divergindo os mesmos quando analisados em função de variáveis como o sexo, a idade, ou a modalidade ou tipo de desporto praticado pelas crianças e jovens ${ }^{(25,45)}$.

No entanto, considerando as limitações e desvantagens que o estudo isolado e ateórico dos motivos para a prática implicava em termos do desejável aprofundamento do conhecimento no domínio da motivação, a investigação rapidamente evoluiu para uma aborda- 
gem baseada em enquadramentos conceptuais previamente definidos, normalmente alicerçados numa matriz de natureza sociocognitiva, colocando a ênfase no modo como os comportamentos dos indivíduos em geral, e das crianças e dos jovens em particular, são influenciados pela sua percepção de competência ${ }^{(38)}$ e pelos critérios de sucesso relativamente a uma determinada actividade $(21,54,55,86)$.

A teoria da motivação para a competência de Harter ${ }^{(37)}$, que tem raízes no trabalho de White ${ }^{(96)}$, prediz que o que move um indivíduo a realizar uma tarefa e envolver-se em determinadas actividades é a necessidade de se sentir competente, pelo que ele tratará de dominar a situação e de pôr à prova a sua eficácia e mestria; porém, é necessário que essa situação/ actividade seja valorizada pelo indivíduo. 0 êxito nessas situações é acompanhado de afecto positivo, promoção da autoestima e de uma sensação de controlo, que incrementa a motivação dos indivíduos para a prática da actividade em questão.

No contexto desportivo, e relativamente à temática do abandono da prática desportiva, esta teoria prediz que os jovens desportistas que se orientam para a prática de uma modalidade e nela persistem têm percepções de competência mais elevadas do que os que a abandonam $^{(9,23,63)}$. Dito de outra forma, o abandono ocorrerá quando os participantes se percebem a si próprios como sendo detentores de reduzida competência.

A percepção de competência é um construto igualmente importante na teoria que se centra nos objectivos de realização dos indivíduos ${ }^{(21)}$. 0 pressuposto fundamental desta teoria é que, em contextos de realização, o principal objectivo dos indivíduos consiste em demonstrarem uma elevada competência e evitarem demonstrar uma competência débil, a si e/ ou aos outros. Esta perspectiva destaca também que o modo como as pessoas definem o sucesso não é uniforme, o que as leva a avaliarem de forma diferente a competência. Assim, temos que uma das principais formas de definir sucesso e avaliar a competência - habitualmente designada como orientação para a tarefa - decorre do recurso a critérios de natureza autorreferenciada, enfatizando o progresso e a melhoria individual (por exemplo, "melhorar o rendimento pessoal" ou "completar uma tarefa com êxito"), enquanto uma outra - habitualmente designada como orientação para o ego - decorre do recurso a critérios normativos ou socialmente comparativos, destacando a comparação com o rendimento dos outros (por exemplo, "ganhar" ou "fazer melhor que os outros").

Na medida em que a motivação dos indivíduos depende da sua competência percebida na actividade, nos exclusivamente orientados para o ego a motivação manter-se-á elevada enquanto consigam mostrar-se superiores aos adversários, diminuindo naturalmente quando esse não for o caso; nestes casos, muitas vezes, ocorre o abandono da prática desportiva como forma de evitar a demonstração de uma reduzida competência e pelo receio de cair em ridículo. Para os indivíduos fundamentalmente orientados para a tarefa, um menor rendimento face aos seus adversários parece não ter as mesmas consequências ao nível da sua motivação, a qual se manterá elevada enquanto sentirem que estão 
a progredir e a ter sucesso nas tarefas que se propõem realizar ${ }^{(54)}$. A este propósito, importará todavia sublinhar que é perfeitamente possível - e mesmo desejável - que as crianças e os jovens recorram a mais do que um critério de sucesso, os quais não são necessariamente incompatíveis entre si.

A investigação no âmbito do desporto nos EUA evidenciou que crianças e jovens com diferentes objectivos de realização apresentavam diferentes perfis motivacionais e diferentes crenças em relação ao sucesso. Em concreto, verificou-se uma associação da orientação para a tarefa com maior satisfação, maior divertimento, maior resistência ao insucesso e maior coesão de grupo, enquanto a orientação para o ego se relacionou com índices mais reduzidos de divertimento e de satisfação com a prática e índices mais elevados de abandono ${ }^{(21)}$. Diversos estudos têm revelado resultados semelhantes na Europa, incluindo Portugal, embora exista ainda espaço para a realização de mais estudos no nosso País antes de se considerar que possuímos um conhecimento aprofundado e consolidado sobre este assunto ${ }^{(28)}$.

A investigação tem demonstrado igualmente que as pessoas não configuram do mesmo modo a natureza e as determinantes da competência desportiva, entendida por uns como fruto do trabalho desenvolvido nesse sentido e por outros como algo geneticamente determinado; de facto, embora, em termos genéricos, as crenças de que a competência desportiva decorre da aprendizagem, é melhorável e específica sejam adoptadas por muitos indivíduos, não é de negligenciar o modo como as crenças de que a competência é determinada por factores de natureza genética, é estável e é generalizável são igualmente identificáveis no ideário dos indivíduos ${ }^{(28,67,68)}$.

De um ponto de vista motivacional, as implicações de uma ou outra perspectiva parecem ser claramente distintas: os jovens que entenderem que a sua competência decorre da aprendizagem, é melhorável e específica orientar-se-ão mais para o seu desenvolvimento, pois acreditam que ela decorrerá essencialmente da sua aplicação nos treinos e jogos; ao invés, os que a considerarem como um dom, estável e geral adoptarão uma posição contrária, esperando-se que não estejam tão disponíveis para um intenso envolvimento em treinos e jogos $(28,29,67,68)$.

Também a teoria da autodeterminação ${ }^{(18,64)}$ permite uma abordagem particularmente interessante para a compreensão da motivação e do abandono no contexto desportivo. Esta abordagem, que consagra igualmente um papel especial à competência percebida, postula que a pessoa é intrinsecamente motivada para uma actividade quando esta the permite a satisfação de três necessidades básicas: i) de competência, isto é, de se sentir competente no que concerne à realização da tarefa ou actividade em que está envolvido; de autonomia, isto é, de se sentir com autonomia e controlo da decisão de realizar aquela tarefa ou actividade; e iii) de pertença social, isto é, de se sentir aceite e ligado aos outros ou pertencente a um determinado meio social ${ }^{(18,90)}$. 
Aplicada ao contexto desportivo, esta teoria pressupõe que elevadas percepções de competência, autonomia e de pertença social levam os indivíduos a envolverem-se de livre vontade e de forma duradoura em actividades e contextos que thes permitam perceberem-se daquela forma ${ }^{(91)}$. De facto, são vários os estudos que fornecem suporte para a sugestão da importância e impacte assumido pela competência percebida ${ }^{(97)}$, pertença social ${ }^{(78)}$ e autonomia ${ }^{(92)}$ ao nível da motivação intrínseca. Segundo Cechinni e colaboradores ${ }^{(11)}$, uma revisão de diversos estudos mostrou que quanto mais autonomia, esforço e progresso são promovidos pelos treinadores mais os atletas se motivam de forma autodeterminada; bem como evidenciou que formas de motivação menos autodeterminada, relacionadas com objectivos orientados para o ego, levavam ao abandono da actividade praticada. A investigação demonstrou ainda que, em geral, a motivação intrínseca se relaciona positivamente com a orientação para a tarefa e negativamente com a orientação para o ego, e permite predizer a intensidade e persistência com que os indivíduos se envolvem na prática de uma certa actividade ${ }^{(61)}$.

Em conclusão, entendemos pois que estes enquadramentos conceptuais que anteriormente referimos, de forma necessariamente breve e resumida, e que são utilizados habitualmente para explicar e compreender questões mais relacionadas com a motivação no desporto, poderão revelar-se como muito úteis para a compreensão do abandono desportivo, sendo este um desafio que deve constituir-se como uma prioridade da investigação, mas também da intervenção, relativa à prática desportiva de crianças e jovens. 
1. Alderman RB (1976). Incentive motivation in sport: An interpretative speculation of research opportunities. In: Fisher AC (ed.), Psychology of sport: Issues $\mathcal{E}$ insights. Palo Alto, California: Mayfield.

2. Alderman RB (1978). Strategies for motivating young athletes. In: Straub WF (ed.), Sport psychology: An analysis of athlete behaviour. Ithaca, NY: Mouvement, 136-148.

3. Alderman RB, Wood NL (1978). An analysis of incentive motivation in young Canadian athletes. Canadian Journal of Applied Sport Sciences, 1: 169-176.

4. Blair SN, Kohl HWIII, Paffenbarger RSJr, Clark D, Cooper KH, Gibbons LW (1989). Physical activity and all-cause mortality: A prospective study of healthy men and women. Journal of the American Medical Association, 262 (17): 2395-2401.

5. Bredemeier BJ, Weiss MR, Shields DL, Shewchuk RM (1986). Promoting mental growth in a summer sport camp: The implementation of theoretically grounded instructional strategies. Journal of Moral Education, 15: 212-220.

6. Brustad RJ (2000). Efeitos da participação no desporto no desenvolvimento psicológico e social das crianças. Conferência apresentada na FCDEF-UP, Porto.

7. Buceta JM (2004). Estrategias psicológicas para entrenadores de deportistas jóvenes. Madrid: Editorial Dykinson. 8. Burhman HG, Bratton R (1978). Athletic participation and status of Alberta high school girls. International Review of Sport Psychology, 12: 57-67.

9. Burton D, Martens R (1986). Pinned by their own goals: An exploratory investigation into why kids drop out of wrestling. Journal of Sport Psychology, 8: 183-197.

10. Campbell S (1986). Youth sport in the United Kingdom. In: Weiss MR, Gould D (eds.), Sport for children and youths. Champaign, Il: Human Kinetics, 21-26.

11. Cecchini JA, Méndez A, Contreras OR (2005). Motivos de abandono de la prática del deporte juvenil. Cuenca: Ediciones de la Universidad de Castilla-La Mancha.

12. Chevallier V (1994). Démographie sportive: Itinéraires et abandons dans les pratiques de l'équitation. Dissertação de Doutoramento. Paris: Université de Paris VII.
13. Chevallier V (1996). Une population de pratiquants sportifs et leurs parcours: Les cavaliers titulaires d'une licence. Population, 3: 573-608.

14. Cruz J, Costa F, Rodrigues RM, Ribeiro FM (1988). Motivação para a prática e competição desportiva. Revista Portuguesa de Educação, 1: 113-124.

15. Cruz JF, Costa F, Viana M (1995). Avaliação da motivação para a competição desportiva: Estudo preliminar dos motivos para a prática e das razões para o abandono. In: Almeida L, Ribeiro I (eds.), Avaliação Psicológica: Formas e contextos (Vol. 3). Braga: APPORT e Universidade do Minho

16. Cruz JF, Machado PP, Mota MP (1996). Efeitos e benefícios psicológicos do exercício e da actividade física. In: Cruz JF (Ed.), Manual de psicologia do desporto. Braga: SHO, 91-116.

17. Cruz JF, Viana M (1989). Motivation in competitive team sports: A study of Portuguese volleyball and handball participants and dropouts. Trabatho apresentado no 7th World Congress of Sport Psychology: Singapore.

18. Deci EL, Ryan RM (2000). The "what" and "why" of goal pursuits: Human needs and the self-determination of behavior. Psychological Inquiry, 11: 227-268. 19. DeKnop P, Vanreusel B, Theeboom M, Wittock H (1996). Belgium. In: DeKnop P, Engstrom L, Skirstad B, Weiss M (Eds.), Worldwide trends in youth sport. Champaign, IL: Human Kinetics, 88-100.

20. Donnelly P, Kidd B (2003). Realizing the expectations: Youth, character, and community in Canadian sport. In: The sport we want: Essays on current issues in community sport in Canada. Canadian Centre for Ethics in Sport, 25-44.

21. Duda JL (1993) Goals: A social-cognitive approach to the study of achievement motivation in sport. In: Singer R, Murphey M, Tennant LK (Eds.), Handbook of research on sport psychology. New York: MacMillan, 421-436.

22. Engstrom, L. (1996). Sweden. In: DeKnop P, Engstrom L, Skirstad B, Weiss M (Eds.), Worldwide trends in youth sport. Champaign, IL: Human Kinetics, 231-243. 
23. Feltz DL, Petlichkoff L (1983). Perceived competence among interscholastic sport participants and dropouts. Canadian Journal of Applied Sport Sciences, 8: 231-235.

24. Ferreira MBR (1986). Youth sport in Brazil. In: Weiss MR, Gould D (eds.), Sport for children and youths. Champaign, IL: Human Kinetics, 11-15.

25. Fonseca AM (1995). Motivos para a prática desportiva: Investigação desenvolvida em Portugal. Agon: Revista Crítica de Desporto e de Educação Física, 1: 49-62.

26. Fonseca AM (ed). (2001). A FCDEF-UP e a Psicologia do Desporto: Estudos sobre motivação. Porto: FCDEF-UP.

27. Fonseca AM (2004). 0 abandono das práticas desportivas: Aspectos psicológicos. In: Gaya A, Marques A, Tani G (Eds.), Desporto para crianças e jovens: Razões e finalidades. Porto Alegre (Brasil): Editora da UFRGS, 265-288.

28. Fonseca AM, Maia J (2000). A motivação dos jovens para a prática desportiva federada: Um estudo com atletas das regiões Centro e Norte de Portugal com idades compreendidas entre os 10 e os 18 anos. Ministério da Juventude e do Desporto e Centro de Estudos e Formação Desportiva.

29. Fonseca AM, Paula-Brito A (2001). Variables motivadoras discriminantes de la intención de practicar actividad física o deporte en estudiantes de secundaria. In: Dosil J (ed.), Psicología y deporte de iniciación. Ourense: Ediciones GERSAM, 55-77.

30. Fry DA, McClements JD, Sefton JM (1981). A report on participation in the Saskatoon Hockey Association. Saskatoon, Canadá: SASK Sport.

31. Gill DL, Gross JB, Huddleston S (1983). Participation motivation in youth sports. International Journal of Sport Psychology, 14: 1-4.

32. Gould D (1987). Understanding attrition in children's sport. In: Gould D, Weiss MR (eds.), Advances in pediatric sciences (Vol. 2). Champaign, IL: Human Kinetics.

33. Gould D, Feltz D, Horn T, Weiss M (1982). Reasons for discontinuing involvement in competitive youth swimming. Journal of Sport Behavior, 5: 155-165.
34. Guillet E (2000). Facteurs et processus de l'abandon sportif: Du role de l'entrainer à l'impact des norms culturelles: Un etude logitudinale en handball féminin. Tese de doutoramento. Grenoble: Universidade Joseph Fourier.

35. Guillet E, Sarrazin P (1999). Utiliser l'analyse de survie pour determiner les moments et les taux d'abandon de la pratique sportive: L'exemple du handball féminin. Trabalho não publicado. Grenoble: Universidade Joseph Fourier.

36. Guillet E, Sarrazin P, Cury F (2001). L'abandon sportif: de l'approache descriptive aux modèles interactionnistes. Science \& Motricité, 41: 47-60.

37. Harter S (1978). Effectance motivation reconsidered: Toward a developmental model. Human Development, 21: 34-64.

38. Harter S (1983). Developmental perspectives on the self-esteem. In: Hetherington EM (ed.) Handbook of child psychology: Socialization, personality and social development (Vol. 4). New York: John Wiley \& Sons, 275-385.

39. Ibsen B, Ottesen L (1996). Denmark. In: DeKnop P, Engstrom L, Skirstad B, Weiss M (Eds.), Worl$d$ wide trends in youth sport. Champaign, IL: Human Kinetics, 101-114.

40. Jefferies SC (1986). Youth sport in the Soviet Union. In: Weiss MR, Gould D (eds.), Sport for children and youths. Champaign, IL: Human Kinetics, 35-40.

41. Kerr $G$ (1996). The role of sport in preparing youth for adulthood. In: Galway B, Hudson J (eds.), Youth in transition: Perspectives on research and policy. Toronto: Thompson Educational Publishing, 293-301.

42. Kleiber D, Roberts GC (1981). The effects of sport experience in the development of social character: An exploratory investigation. Journal of Sport Psychology, 3: 114-122.

43. Klint KA, Weiss MR (1986). Dropping out and in: Participation motives of current and former youth gymnastics. Canadian Journal of Applied Sport Sciences, 11: 106-114.

44. Kohl HWIII, Laporte RE, Blair SN (1988). Physical activity and anger: An epidemiological perspective. Sports Medicine, 66: 222-237. 
45. Koivula N (1999). Sport Participation: Differences in motivation and actual participation due to gender typing. Journal of Sport Behavior, 14 (1): 3-18.

46. Kremer J, Trew K, Ogle S (eds.) (1997). Young people's involvement in sport. London: Routledge.

47. Laakso L, Telama R, Yang X (1996). Finland. In: DeKnop P, Engstrom L, Skirstad B, Weiss M (Eds.), Worldwide trends in youth sport. Champaign, IL: Human Kinetics, 126-138.

48. Marivoet S (2001). Hábitos desportivos da população portuguesa. Lisboa: INFED/ MJD.

49. Martens R (1986). Youth sport in the USA. In: Weiss MR, Gould D (eds.), Sport for children and youths. Champaign, IL: Human Kinetics, 27-33.

50. Martinsen EW (1995). The effects of exercise on mental health in clinical populations. In: Biddle SJH (ed.), European perspectives on exercise and sport psychology. Champaign, IL: Human Kinetics, 71-84.

51. Must A, Strauss RS (1999). Risks and consequences of childhood and adolescent obesity. International Journal of Obesity, 23 (Suppl. \#2): S2-S11.

52. Mutrie N, Biddle SJH (1995). The effects of exercise on mental health in nonclinical populations. In: Biddle SJH (Ed.), European perspectives on exercise and sport psychology. Champaign, IL: Human Kinetics, 50-70.

53. National Center for Education Statististics (1989). Projections of educational statistics to 2000. Reston, VA: National Association for Sports and Physical Education.

54. Nicholls J (1989). The competitive ethos and democratic education. Cambridge, MA: Harvard University Press.

55. Nicholls $J$ (1992) The general and the specific in the development and expression of achievement motivation. In: Roberts G (Ed.) Motivation in sport and exercise. Champaign, IL: Human Kinetics, 31-56.

56. Paffenbarger RS, Hyde RT (1984). Exercise in the prevention of coronary heart disease. Preventive Medicine, 13: 3-22.

57. Petlichkoff LM (1992). Youth sport participation and withdrawal: Is it simply a matter of fun? Pediatric Exercise Science, 4: 105-110.

58. Pooley JC (1981). Drop-outs from sport: A case study for boys age-group soccer. Trabalho apresentado na Conferência da AAHPERD, Boston, EUA.
59. Powell KE, Thompson PD, Caspersen CJ, Kendrick JS (1989). Physical activity and the incidence of coronary heart disease. Annual Review of Public Health 8: 253-287.

60. Puig N (1996). Spain. In: DeKnop P, Engstrom L, Skirstad B, Weiss M (Eds.), Worldwide trends in youth sport. Champaign, IL: Human Kinetics, 222-230.

61. Roberts GC (1992). Motivation in sport and exercise: Conceptual constraints and convergence. In: Roberts GC (ed). Motivation in sport and exercise. Champaign, IL: Human Kinetics, 3-29.

62. Roberts GC, Kleiber GA (1982). The importance of perceived ability in the developing child's participation of recreation and sport. Comunicação apresentada à NRPA Annual Meeting. Louisville.

63. Roberts GC, Kleiber DA, Duda JL (1981). An analysis of motivation in children's sport: The role of perceived competence in participation. Journal of Sport Psychology, 3: 206-216.

64. Ryan RM, Deci EL (2000). Intrinsic and extrinsic motivations: Classic definitions and new directions. Contemporary Educational Psychology, 25: 54-67.

65. Sallis JF, McKenzie TL, Lolody B, Lewis M, Marshall S, Rosengard P (1999). Effects of health-related physical education on academic achievement. Research Quarterly for Exercise and Sport, 70 (2): 127-134.

66. Sarrazin P (2002). L'abandon sportif: Causes et processus. Comunicação apresentada ao III Colloque Médico Technique du Ski Alpin.

67. Sarrazin P, Biddle SJH, Famose JP, Cury F (1996) Goal orientations and conceptions of the nature of sport ability in children: A social cognitive approach. British Journal of Social Psychology, 35 (3): 399-414.

68. Sarrazin P, Famose JP, Biddle SJH, Fox K, Durand M, Cury F (1995). Buts d'acomplissment et croyances relatives à la nature de l'habilité motrice. Science $\mathcal{E}$ Motricité, 26: 21-31.

69. Sarrazin P, Guillet E (2001). Mais pourquoi ne se réinscrivent-ils plus! Variables et processus de l'abandon sportif. In: Cury F, Sarrazin P (eds.). Théories de la motivation et pratiques sportives: État des recherches. Paris: PUF, 223-254.

70. Sarrazin P, Guillet E, Cury F (2001). The effect of coach's task- and ego-involving climate on the chan- 
ges in perceived competence, relatedness, and autonomy among girl handballers. European Journal of Sport Sciences, 1 (4): 1-9.

71. Schaffer WE (1969). Participation in interscholastic athletics and delinquency: A preliminary study. Social Problems, 17: 40-47.

72. Seefeldt $V$ (1995). Recreating recreation and sports in Detroit, Hamtramck and Highland Park: Final report to the Skillman Foundation. Detroit, MI: The Skillman Foundation

73. Seefeldt VD, Ewing ME (2000). Youth sports in America: An overview. President's Council on Physical and Sports Research Digest, 2 (11).

74. Sefton JM, Fry DA (1981). A report on participation in competitive swimming. Saskatoon: Canadian Amateur Swimming Association.

75. Segrave JO (1983). Sports and juvenile delinquency. Exercise and Sports Science Review, 2: 161-209.

76. Segrave JO, Hastad D (1982). Delinquent behaviour and interscholastic participation. Journal of Sports Behavior, 5: 96-111.

77. Siscovick DS, Laporte RE, Newman JM (1985). The disease-specific benefits and risks of physical activity and exercise. Public Health Reports, 100: 181-188.

78. Smith AL (1999). Perceptions of peer relationships and physical activity participation in early adolescence. Journal of Sport \& Exercise Psychology, 21: 329-350.

79. Smith RE, Smoll FL (1991). Behavioral research and intervention in youth sports. Behavior Therapy, 22: 329-344.

80. Smith RE, Smoll FL (1996). Psychosocial interventions in youth sport. In: Van Raalte $\mathrm{JL}$, Brewer BW(eds.), Exploring sport and exercise psychology. Washington, DC: American Psychological Association, 287-315.

81. Smith RE, Smoll FL (1997). Coaching the coaches: Youth sports as a scientific and applied behavioral setting. Current Directions in Psychological Science, 6 (1): 16-21.

82. Smith RE, Smoll FL, Barnett NP (1995). Reduction of chidren's sport performance anxiety trough social support and stress-reduction training for coaches. Journal of Applied Developmental Psychology, 16: 125-142.
83. Smith RE, Smoll FL, Curtis B (1979). Coach effectiveness training: A cognitive-behavioral approach to enhancing relationship skills in youth sport coaches. Journal of Sport Psychology, 1: 59-75.

84. Smoll FL (1988). A comunicação do treinador com os pais dos atletas (trad.). Lisboa: Direcção-Geral dos Desportos.

85. Swabey K, Rogers A (1997). Sports after high school? An investigation into the sports drop out of students in the transition from high school to college. Disponível em http://www.aare.edu.au/97pap/ swabk111.htm.

86. Thill EE (1989). Motivation et strategies de motivation in milieu sportif. Paris: PUF.

87. Trabal B, Agustini M (1997). L'abandon de la pratique de la boxe française. In: Congrès International des Chercheurs en Activités Physiques et Sportives, Actes... (7). Marseille.,

88. Turner S, Brown D, Buist A, Fafard M, Goulet C (2003). Best practices in sport: a vehicle for positive values and ethical conduct. In: The sport we want: Essays on current issues in community sport in Canada. Canadian Centre for Ethics in Sport, 102-125.

89. Valeriote TA, Hansen L (1986). Youth sport in Canada. In: Weiss MR, Gould D (eds.), Sport for children and youths. Champaign, IL: Human Kinetics, 17-20.

90. Vallerand RJ (1997). Toward a hierarchical model of intrinsic and extrinsic motivation. In: Zanna MP (ed.), Advances in experimental social psychology (vol. 29). New York: Academic Press, 271-360.

91. Vallerand RJ (2001). A hierarchical model of intrinsic and extrinsic motivation in sport and exercise. In: Roberts GC (ed.), Advances in motivation in sport and exercise. Champaign, IL: Human Kinetics, 263-320.

92. Vallerand RJ, Losier GF (1999). An integrative analysis of intrinsic and extrinsic motivation in sport. Journal of Applied Sport Psychology, 11: 142-169.

93. Weiss MR, Chaumeton N (1992). Motivational orientations in sport. In: Horn T (ed.), Advances in sport psychology. Champaign, IL: Human Kinetics, 61-101.

94. Weiss MR, Hayashi CT (1996). The United States. In: DeKnop P, Engstrom L, Skirstad B, Weiss M (Eds.), Worldwide trends in youth sport. Champaign, IL: Human Kinetics, 43-57.

\section{6}

(n)


95. White A, Rowe N (1996). England. In: DeKnop P, Engstrom L, Skirstad B, Weiss M (Eds.), Worldwide trends in youth sport. Champaign, IL: Human Kinetics, 115-125. 96. White RW (1959). Motivation revisited: The concept of competence. Psychological Review, 66: 297-333.

97. Williams JM, Gill DL (1995). The role of perceived competence in the motivation of physical activity. Journal of Sport \& Exercise Psychology, 17: 363-378. 